\title{
Anemia in preschool children from Angola: a review of the evidence
}

\author{
Cláudia Fançony, $\mathrm{MD}^{\mathrm{a}, \mathrm{b}} *$, João Lavinha, $\mathrm{PhD}^{\mathrm{c}, \mathrm{d}}$, Miguel Brito, $\mathrm{PhD}^{\mathrm{a}, \mathrm{e}}$, Henrique Barros, $\mathrm{PhD}{ }^{\mathrm{b}}$
}

\begin{abstract}
Angola is one of the southern African countries with the highest prevalence of anemia, and despite the high geographic heterogeneity of its distribution across the country, it was reported to be indicative of a severe public health problem in some areas, mainly in children. Despite the relevance of this condition in the country there is still an important gap regarding scientific evidences and knowledge systematization in the indexed literature, that could be used to inform and optimize national public health policies willing to address it. Furthermore, the changes in anemia epidemiology among African preschool children and the late updates in nutritionspecific and nutrition-sensitive preventive strategies in the continent are of imperative relevance, as they could contribute to design context-specific national approaches to reduce anemia's morbidity and mortality. In this study we intent to perform a systematic review regarding the sparse evidence available on the country regarding the prevalence of anemia, its associated factors, the prevention, and/or control strategies with potential to reduce anemia that were implemented, and to discuss interventions targeting infections and/or nutrition conducted in other African countries.
\end{abstract}

Keywords: Africa, anemia, Angola, associated factors, preschool children, prevalence

\section{Introduction}

The prevalence of anemia in 2011 for 6- to 59-month children from the WHO's African region, was $62 \%$, presenting a substantial geographic variability. ${ }^{1}$ For instance, in that year, Tunisia, Libya, Algeria, Morocco, Seychelles, and Rwanda had the lowest prevalence's in Africa (29\%-38\%), followed by South Africa, Botswana, Djibouti, Mauritius, Swaziland, Egypt, Kenya, Burundi, Lesotho, Namibia, Ethiopia, and Madagascar (41\%$50 \%$ ); Comoros, Angola, Uganda, Somalia, Zambia, Eritrea, Sao Tome and Principe, Sudan, Zimbabwe, Cabo Verde, and Gabon $(51 \%-60 \%)$; Tanzania, Cameron, Benin, Congo, Gambia, Malawi, Mozambique, and Democratic Republic of Congo $(61 \%-67 \%)$; and the remaining countries of the continent having the highest prevalence's $(71 \%-86 \%) .{ }^{1}$ Temporal variations were also observed among those countries, presenting sex- and age-

\section{$M B$ and HB Equivalent co-senior authors. \\ Sponsorships or competing interests that may be relevant to content are disclosed at the end of this article. \\ ${ }^{a}$ Health Research Center of Angola (CISA), Angola Bengo province, Caxito city, ${ }^{b}$ Institute of Public Health, University of Porto, Porto, ${ }^{C}$ Department of Human Genetics, National Institute of Health Dr. Ricardo Jorge, ${ }^{d}$ BiolSI, Faculty of Science, University of Lisboa, ${ }^{e}$ Health and Technology Research Center (H\&TRC), Escola Superior de Tecnologia da Saúde de Lisboa, Instituto Politécnico de Lisboa, Lisboa, Portugal.}

* Corresponding author. Centro de Investigação em Saúde - Instituto Nacional de Investigação em Saúde. Rua Amilcal Cabral 96, Maianga, Luanda Angola. E-mail address: cisa.cfv@gmail.com (Cláudia Fançony).

Copyright (C) 2020 The Authors. Published by Wolters Kluwer Health, Inc. on behalf of PBJ-Associação Porto Biomedical/Porto Biomedical Society. All rights reserved.

This is an open access article distributed under the terms of the Creative Commons Attribution-Non Commercial-No Derivatives License 4.0 (CCBY-NCND), where it is permissible to download and share 3the work provided it is properly cited. The work cannot be changed in any way or used commercially without permission from the journal.

Porto Biomed. J. (2020) 5:1(e60)

Received: 3 July 2019 / Accepted: 6 January 2020

http://dx.doi.org/10.1097/j.pbj.0000000000000060 specific variabilities. ${ }^{2-5}$ For instance, the number of countries with prevalence's $>50 \%$ decreased significantly between 1990 and 2010, decreasing more for males and having negative trends in children younger than 5 years. ${ }^{6-9}$

Consistently, this prevalence variability is also followed by variations in the morbidity associated to this condition. For instance, age-adjusted analysis in studies conducted in 2013, showed that the burden of anemia was more concentrated in western and central sub-Saharan Africa, possibly indicating a greater severity of disease and higher prevalence of its etiologies in those regions. ${ }^{6}$ Kassebaum et al, $^{9} 2014$ reported that areas where the prevalence of anemia is high, may also have higher burden of anemia related to infectious and iron-related etiologies. In accordance, the achievements reported for the Eastern subSaharan Africa in 2013 may possibly be also attributed to the implementation of programs that have likely reduced the causes of anemia, such as improvements in health, poverty, and living conditions (unrelated to the health system). ${ }^{6,9}$ Nevertheless, the combination of improvements leading to those changes still need further clarification. Also, the context-specific etiologic profile of anemia was also suggested to be a crucial factor, influencing anemia's associated mortality. ${ }^{10-15}$ For instance, in Kenia, malaria, bacteremia, and chronic diarrhea were reported to be responsible for $12.2 \%, 8.7 \%$, and $32 \%$ of the anemia-related deaths, contrasting with Ghana where nutritional anemia, severe malaria, and sickle cell anemia caused respectively, $52.1 \%$, $21.6 \%$, and $10.8 \%$ of those deaths. ${ }^{11-14}$ Furthermore, in Zaire, severe anemia caused by iron deficiency was reported to be the second greatest cause of death in children younger than 5 years, and in Gambia, the seasonal variations of malaria and anemia were similar, with the peak mortality in young children occurring when both were most prevalent. ${ }^{11,15-17}$

In Angola, the southern African country with the highest prevalence rate in 1990, Kassebaum et $\mathrm{al}^{6,9} 2016$ reported a similar tendency of decreasing prevalence (from 50\%-60\% to $40 \%-50 \%$ for all ages). However, the availability of holistic and public health-relevant data concerning the anemia associated factors, that could in turn be used to design adequate and 
context-specific interventions, is inexistent. In this study we intent to (1) perform a systematic review regarding the sparse evidence available on the prevalence and factors associated with the occurrence of anemia in the country and regarding prevention and/or control strategies that were implemented in national territory with potential to reduce anemia and (2) to discusses interventions targeting infections and/or nutrition conducted in other African countries.

\section{Methods}

The MESH terms were defined according to the research question. In general, they were introduced in the PubMed to screen for scientific papers, whereas Google search was used to screen for relevant reports. After introducing the MESH terms in the databases and research engines, the abstracts returned from the search were inspected for eligibility. Furthermore, studies were considered eligible if they reported in the abstract the prevalence of anemia, its related factors, and associations or interventions conducted. Studies conducted in animals, population older than 4 years, outside of Africa, regarding hereditary or acquired hemolytic or aplastic anemia, nontarget infections (HIV, etc) or in other language than English were excluded. After selecting the review papers for complete reading, the data relevant to each research question was extracted and resumed for integration in the respective section of this article. Back and forward cross references were conducted whenever found relevant.

\section{Research question: prevalence of anemia and its associated factors in children younger than 5 years in Angola}

Pubmed search. To investigate all studies related to anemia conducted in Angola we used the MESH "( "anaemia”[All Fields] OR “anemia”[MeSH Terms] OR “anemia”[All Fields]) AND ("Angola”[MeSH Terms] OR “Angola”[All Fields])", from this search resulted 54 papers. After considering the exclusion criteria, 46 papers were excluded: 35 for comprehending unrelated diseases, condition, or scope (mainly hemolytic hereditary anemia), 2 studies for unsuitable design (study protocol or laboratory methodological research), 5 studies due to noninclusion of under 5 years old, 3 for unavailable abstract and 1 conducted outside Angola. The full texts of the remainder 9 papers were then critically reviewed. From those, 2 policy papers and 1 reporting results from another paper already reviewed were excluded. The remaining papers were resumed in a table.

Google search. For this search we used the keywords: "Anemia em Angola" plus "Anemia in Angola," to include both results in Portuguese and English. Furthermore, only pdf files resulting from the search were inspected for eligibility. This search resulted in 12 pdf files, 11 in Portuguese and 1 in English. After full text inspection, 9 documents were excluded because their main scope was unrelated to anemia or associated etiologies, and data regarding the prevalence of anemia in preschool children was extracted from the remaining 3 files.

\section{Results}

\section{Review of evidence-anemia in Angola}

There is lack of evidence in Angola regarding the prevalence of anemia and the determinants that influence its occurrence. In addition, concerning is the fact that (as far as we know) there are no published studies specifically targeting the prevention or control of anemia. In this study, the data on what is causing anemia are almost inexistent, as also the available data on preventive and control strategies implemented within national territory. The results of studies that include prevalence of anemia and/or their etiologies and studies of interventions impacting the anemia's occurrence are presented here.

Prevalence and associated factors in Angola. It was reported that in 1992 there was a high proportion (approximately 39\%) of children aging between 3 months and 13 years with hemoglobin $<6.8 \mathrm{mmol} / \mathrm{L}$, occurring mainly in children from low social and economic state (in which the anemia frequency was in turn associated with physical development). ${ }^{18}$ Later, reports from the WHO mentioned that the prevalence for Angolan preschool children between 1998 and 1999 was $29.7 \%$, representative of a moderate public health problem. ${ }^{19}$ In 2011 , the strong relationship between anemia and malaria was evidenced nationally by the Malaria Indicators Survey conducted in the country, suggesting that malaria-infected children were at a higher risk of anemia, and that areas with the highest prevalence of malaria had higher proportion of severe anemia $(4 \%$ of the children in the hyperendemic region had hemoglobin lower than $8.0 \mathrm{~g} / \mathrm{dL}$, whereas $2 \%$ of the children living in the hipoendemic region of Luanda had it). Furthermore, associations between the occurrence of anemia and lower social strata were reinforced. ${ }^{20}$ Between 2015 and 2016, the national multiple indicators survey, reported alarming prevalence in children younger than 5 years $(65 \%) .{ }^{21}$ In that age group, the prevalence was reported to be higher in 6 to 11 months children (83\% in 6-8 months and $82 \%$ in 9-11 months children) and to have higher severity in 12-17 months children with $9 \%$ of moderate-to-severe anemia. ${ }^{21}$ In addition, geographic heterogeneity was documented, with the prevalence ranging from $50 \%$ in Lunda Sul and $77 \%$ in Cuando Cubango.

Regionally, comprehensive studies conducted within the Dande municipality of the Bengo's province in 2010 reported that the prevalence of anemia in children younger than 5 years was $57 \%$ and that malaria and schistosomiasis were responsible for $16 \%$ and $10 \%$ of anemia cases, whereas ascariasis was associated with undernutrition (in turn responsible for $13 \%$ of anemia cases). ${ }^{22,23}$ In that area, the distribution of anemia was found to be heterogeneous and to be influenced by the distribution of malaria. Between 2012 and 2013, Lemos et $\mathrm{al}^{24}$ tested a therapeutic intervention in children (with 2-15 years) from a highly Schistosoma haematobium endemic setting of that province in which the prevalence of anemia at the baseline was very high $(76 \%)$. In the studied children, $76 \%$ had $S$ haematobium, $31 \%$ had at least 1 soil-transmitted helminth, $10 \%$ had Hymenolepis nana, and $6.7 \%$ had Plasmodium falciparum. The study also reports that, among the children followed, all anemia cases were infected with $S$ haematobium. ${ }^{24}$

Interventions with potential two reduce anemia implemented

in Angola. Using the described methodology, we have documented only to interventional studies. Lemos et al, ${ }^{24}$ tested a therapeutic intervention in children (with 2-15 years) from a highly $S$ haematobium endemic setting of that province in the Bengo province, between 2012 and 2013. In sum, authors reported low effectiveness in reducing infections when a mass administration of praziquantel was conjugated with albendazole and an antimalarial test-and-treat approach to malaria-infected children, describing that prevalence reductions 1 month after 
treatment were relevant for urogenital schistosomiasis and intestinal parasites, but that 6 months later the prevalences were similar to the ones at the baseline. ${ }^{24}$ In addition, the variation in the prevalence of $P$ falciparum was postulated to have been biased by the seasonality of malaria (which increased 1 month after treatment but decreased 6 months after), whereas the very high prevalence of anemia was observed to have nonsignificant reduction. $^{24}$ Those results reiterate the high prevalence of infections and anemia in Angola and suggest that the beneficial effect of exclusively therapeutic interventions may not be sustained in our setting, possibly due to heavy contaminated environments. On the contrary, the effectiveness of nutritionspecific interventions needs also to be further investigated. The second study reported that anemia was reduced from $54.1 \%$ to $13.4 \%$ in malaria-infected children treated and from $53.1 \%$ to $15.9 \%$ in children treated with Artesunate-Amodiaquine, and followed by 28 days. $^{25}$

\section{Discussion}

\section{Main strategies to reduce anemia}

Resulting from the review of the evidence available in Angola that was mentioned above, the prevalence suggests the occurrence of anemia in children younger than 5 years as a severe public health problem, in turn associated with either proximal or distal determinants. The main immediate determinants reported are infections, mainly malaria and schistosomiasis. Furthermore, malnutrition has been regionally associated, but data available are very scarce. In fact, designing strategies to reduce anemia requires previous baseline characterization that includes determining the context-specific profile, composed by documentation of anemia's frequency, spatial distribution, risk groups affected, and the contribution of its determinants. This review was unable to provide the necessary data due to scarce and/or publicly unavailable results.

Nevertheless, based on general knowledge, nutrition-specific approach, targeting mainly the immediate determinants of anemia, a nutrition-sensitive approach, targeting fundamental/ basic, underlying and intermediate determinants, or a combination of both should be considered. ${ }^{26}$ Although defining the immediate determinants (nutritional, infectious, and/or genetic) would allow designing short-term control strategies, and determining the relevance of fundamental/basic, underlying, and intermediate determinants would allow designing mediumto-long term prevention strategies, a combination of both would comprehend control and preventive dimensions and could tackle anemia more comprehensively. ${ }^{8,16,27}$ For the purpose of guiding future strategies targeting nutritional anemia in Angola, the rational for some nutrition-specific and nutrition-sensitive approaches are resumed bellow as also the results from some interventional African studies.

Nutrition-specific approach: food-based interventions. Foodbased interventions can aim at (1) increasing the production, availability, and access to micronutrient rich foods, (2) increasing the consumption of micronutrient-rich foods (improving either the overall quantity or quality of multiple erythropoietic micronutrient), (3) increasing the bioavailability of micronutrients in the diet (by increasing the consumption of enhancers and decreasing the consumption of inhibitors of nonheme iron absorption), or (4) combining some of those aspects. ${ }^{8,28-30}$ Their overall goal is to empower individuals to improve the quality of their own diets and are reported as being sustainable for preventing anemia (mainly Iron Deficiency Anemia) or related micronutrient deficiencies. ${ }^{8,27,31,32}$ These approaches can be delivered through education, communication, social marketing, and behavior changing programs to target specific groups, and in young children they are frequently oriented to improve ageadequate breastfeeding, dietary diversity (frequently accounting for increasing micronutrient bioavailability), and feeding frequency. ${ }^{7,16,31,33-43}$ Considering its relevance, the diet diversification and micronutrient bioavailability strategies are briefly discussed below.

Diets in rural areas from developing countries were reported to be based mainly in cereals, starchy roots, and/or tubers and legumes, having normally less frequent consumption of dairy products and flesh foods (which are rich sources of readily available heme-iron, zinc, and vitamin $\mathrm{A}$ as retinol, probably associated to disadvantaged dynamics of anemia-related determinants mentioned above. ${ }^{44,45}$ Plant-based diets are reported to have high content in phytic acid, dietary fibers, and polyphenol, components that may inhibit the absorption of important trace minerals (mainly nonheme iron and zinc), and unsurprisingly, that pattern was reported not to provide the daily needs of calcium, iron, and zinc. ${ }^{28,29,46-49}$ In addition, they frequently have low fat content, which further limit the absorption of lipidsoluble vitamins. When considering dietary diversification to tackle micronutrient deficiency in those settings, it should be considered that the simultaneous consumption of nonheme ironrich foods, and enhancers of iron absorption (citric, malic, or ascorbic acid) or heme iron-rich foods (such as meat, poultry, or fish) may improve iron absorption by limiting the effect of iron inhibitors. ${ }^{50}$ Furthermore, it should also be taken into account that the consumption of legumes, green leafy vegetables, whole grains, and fruits/fruit juices may potentially increase folate levels naturally, the consumption of green leafy vegetables, orange and/ or yellow fruits, vegetables, dairy products, eggs, and fish may increase vitamin A levels, and animal-source foods (such as shellfish, meats, fish, poultry) and dairy products may increase the levels of vitamin B12. ${ }^{16}$ Furthermore, some methods of food processing (soaking, fermentation, germination, or thermal or mechanical processing) may also alter the bioavailability and absorption of micronutrients. ${ }^{16,28}$

\section{Nutrition-sensitive approach-preventing and reducing in-} fection-related anemia. Infections can cause anemia indirectly by causing malabsorption of nutrients or anorexia, but also directly through hemoglobin loss (by blood loss in urine and stool, hemolysis) or impaired red blood cell production (through inflammatory response). ${ }^{51-53}$ Hookworms (Necator americanus and Ancylostoma duodenale) and schistosomes (particularly $S$ haematobium) were reported to be the largest direct contributions to anemia through blood loss..$^{1,5,54-56}$ For instance, published report estimates that one half of moderate-to-severe cases of anemia in children may occur due to hookworm infection. ${ }^{7,16,57}$ Nevertheless, the intensity of infection, and coinfection with multiple parasites determine the severity of blood loss. ${ }^{16,57}$ In addition, schistosomiasis may also contribute to anemia through splenic sequestration of erythrocytes, increased hemolysis, or inflammation due to chronic disease. ${ }^{16}$ Besides leading to a less severe blood loss, Ascaris lumbricoides infection also influences the iron status through gastric and intestinal ulceration and others such as Trichuris trichiura or Giardia lamblia are associated with malabsorption of micronutrients. Malaria associates with severe anemia by causing acute 
and chronic hemolysis, subsequent suppression of erythropoiesis, and possibly secondary folate deficiency. ${ }^{8,16,58,59}$ Because enteric nematodes, cestodes, trematodes, and protozoans are often coendemic, polyparasitism has been suggested to have interactive effects, potentially altering the pathology of anemia. ${ }^{51,60-63}$ For instance, coinfection between Plasmodium and Schistosoma was reported to have a multiplicative protective effects on anemia (in 5-18 years participants), with coinfected children having higher hemoglobin levels than children only infected with $P$ falciparum. ${ }^{62,64}$ Several other infections were also associated with anemia, namely viral and bacterial infections. ${ }^{65}$

It is also important to keep in mind that, while some parasites are the cause of micronutrient deficiencies, the nutritional status of the host can also influence the establishment of the infection itself and influence the pathway by which they will lead to anemia (dependent on the micronutrient that is lacking). ${ }^{58,59,66}$ For instance, when facing a malaria infection, pre-established vitamin A deficiency may contribute to anemia by increasing the susceptibility to parasitemia, modulating iron metabolism, and impairing immune function, whereas vitamin E deficiency may lead to oxidant damage and consequent hemolysis. Moreover, folate and iron deficiency may impair erythrocyte synthesis, whereas riboflavin deficiency may decrease iron absorption and increase erythrocyte fragility, and zinc deficiency may impair immune function, increasing parasitemia, and leading to oxidative damage. ${ }^{58}$ Interestingly micronutrient deficiencies can also protect against malarial anemia, specifically, vitamin E deficiency may protect from anemia by preventing antioxidant activity which increases the susceptibility of malaria parasites to oxygen radicals, whereas riboflavin deficiency may reduce parasite multiplication and growth, folate deficiency may impair the parasite metabolism, and iron deficiency may impair parasite multiplication. ${ }^{58}$

Nutrition-sensitive approach address mainly underlying and basic causes of anemia from a wide range of sectors, including disease control, water, sanitation, and hygiene and intersectoral strategies that address root causes (eg, poverty, lack of education, and gender norms). The control of parasitic infections aim both at stopping transmission (by treating infection) and also at reducing the morbidity that they cause (such as anemia). Anemia evaluation is suggested to be used as additional indicators to monitor population response to interventions in settings with high infection transmission due to relevant infection-anemia relationship. ${ }^{53}$ In order to achieve the nutrition-sensitive approach aims, generally 3 main strategies are adopted: (1) pathogen-targeted chemotherapy that can bring direct relief from disease, promote child development, and help slow transmission; (2) long-term programs such as vector control; Water, Sanitation, and Hygiene (WASH) measures; or health education to change behavior that will help to prevent transmission; (3) a combination of both strategies. ${ }^{7,53,67}$ The plausibility of those interventions is based on the assumption that in poor settings, where high prevalence, intensity, reinfection, incidence, and co-endemicity of anemia-related infections occur, there is an important contribution of micronutrient deficiency anemia related to infections, potentially refractory to supplementation and requiring multicausal resolution approaches. . $23,68-71$ In addition, in setting with a highly infectious profile, the screening and treatment of infections must be provided (especially in the case of malaria), to further prevent supplementation to adversely affect the infectionassociated morbidity and mortality in children. ${ }^{27,72-76}$

One of the first infection to be considered is malaria, responsible for approximately $35 \%$ of anemia in African children, and whose control in endemic areas was reported to greatly reduce anemia and severe anemia (by $>25 \%$ and by $60 \%$, respectively). ${ }^{16,23,25,77-81}$ When prevention is to be considered, chemoprevention and vector control are frequently planned. Intermittent preventive treatment comprehends the administration of sulfoxide-pyrimethamine, designed to protect children against clinical malaria and anemia in the first year of life, whereas vector control is the key intervention for global malaria control, aiming mainly at increasing the use of long-lasting insecticidal nets and indoor residual spraying to decrease transmission (among other less frequently used strategies). ${ }^{7,16,77}$ The increased use of insecticide-treated nets has been reported to be successfully followed by significant decrease in the moderateto-severe anemia among children aging between 6 and 23 months of age. ${ }^{77}$

Soil-transmitted helminths, schistosomiasis, and environmental/tropical enteropathy (caused by the ingestion of high amount of fecal bacteria), should also be considered, as they are associated to anemia (mainly IDA) as previously reported. ${ }^{16,82-85}$ Therapeutic approaches, aiming at reducing the burden of soil-transmitted helminths infections and the intensity of infections, include single-dose, large-scale mass deworming, periodic preventive chemotherapy, or repeated large-scale administration of anthelminthic drugs to at-risk populations (preschool, school-aged children, and women of childbearing age). ${ }^{86,87}$ For schistosomiasis, control includes large-scale drug treatment of at-risk populations (with praziquantel), snail control, improved sanitation, and health and hygiene education. Until recently, target populations included school-aged children and adults (with occupations involving contact with infested water) considered to be at risk or entire communities in endemic areas. New evidences of high prevalence among preschool children has, however, highlighted the need to include them in control strategies. ${ }^{88-92}$ Furthermore, multisectoral strategies, targeting adequate water, sanitation, and hygiene practices may maximize and sustain the benefits of a decreased burden of those infections. For instance, promoting improvements in key hygiene behaviors (such as hand washing), treatment, and use of safe water, and using hygienic methods of disposal of feces and urine can be incorporated into health-sector activities, such as nutrition counseling, promotion, and assessments, as well as health visits.

Combining strategies to reduce anemia. Integrating therapeutic (deworming) and preventive (either food-based or WASH/ malaria education) strategies can simultaneously treat infections and increase hematopoietic micronutrient intake or reduce disease transmission, which could result in the reduction of malnutrition and anemia. ${ }^{7,31,33-40,69,86,87,93-97}$ For instance, deworming plus nutrition education has been reported to reduce anemia from $82.0 \%$ to $55.4 \%$, while increasing green leafy vegetables consumption from $44.7 \%$ to $60.6 \%{ }^{40}$ Furthermore, exclusive educational interventions targeting nutrition improvement; increased ability of mothers to identify malnutrition (from $15 \%$ to $99 \%$ ); exclusive breastfeeding ( $79 \%$ vs $48 \%$ in control); weight gain ( 0.86 vs $0.77 \mathrm{~kg}$ in control); vegetables feeding; nutrient-dense foods at lunch $(11 \%$ of difference between intervention and control groups); dietary requirements for energy, iron, and zinc; complementary feeding; and significantly reduced rates of stunting. ${ }^{3-37,41,98}$ On the contrary, exclusive WASH educational interventions, health education on soiltransmitted helminths and schistosomiasis, significantly increased knowledge, reduced the prevalence of $A$ lumbricoides 
and $S$ mansoni, and reduced the incidence of hookworms and the intensity of trichuriasis, ascaridiasis, and hookworms. ${ }^{87,93}$ When deworming is added to WASH education, prevalence and intensity of soil transmitted helminths decrease and school children scored higher than control on their knowledge. ${ }^{86,93}$ Studies evaluating educational approaches to malaria prevention showed improved knowledge regarding breeding sites, bed-net use and indoor spraying, increased windows and door net use and practice of maintaining clean environment and, a reduced number of reported malaria episodes and fever incidence, ${ }^{94,95,99,100}$

As mentioned, several comprehensive intervention strategies have correspondingly been tested. They, however, frequently evaluate the impact of education on nutrition or on infectious etiologies (whether or not combined with drug therapy) separately. ${ }^{33-40,86,87,93-96}$ Thus, differences in their designs and methodologies hinder the face to face comparison and evaluation of results, rendering it difficult to define the best approach to reduce anemia. For instance, differences on the target population (adult or children), dimensions of the learning package (eg, for sanitation: stool disposal, water quality, or supply), the deliverers (community promoters/volunteers, teachers, local health workers, community leaders), the place where education occurs (at health center or at the communities), the number of intervention contacts, type of contacts (group meetings and/or individual contacts), and duration of the intervention/observation and mainly the combination with other strategies (micronutrient supplementation, construction of latrines, and hand-washing mechanisms, etc) can be observed. ${ }^{33-40,86,87,93-96}$ Furthermore, one of the most inclusive studies, published recently by Humphrey et $\mathrm{al}^{101} 2019$, investigated the effect of 2 WASH interventions, either alone or combined with improved Infant and Young Child Feeding, concluding that education in nutrition reduce anemia and stunting, but adding WASH to the intervention had no major improvements on those effects. Similar results were reported by Null et $\mathrm{al}^{102} 2018$ within a cluster-randomized trial using interventive groups with several WASH and nutrition combinations. Neither study investigated the effect of combining deworming, nor was the impact of malaria preventive actions included.

\section{Other aspects that need to be considered when designing interventions}

Genetic causes of anemia. The normal adult hemoglobin molecule is composed of 4 globin subunits ( $2 \alpha$ and $2 \beta$ ), 1 heme pigment (bound to each globin chain) including 1 iron (II) atom in each heme pigment. Furthermore, $>1000$ human hemoglobin variants have been described in the literature, a number of which are abnormal types of hemoglobin. ${ }^{27,103,104}$ These abnormalities may result from mutation in the globin structural genes (with consequent qualitatively or quantitatively abnormal hemoglobin), or from mutations in globin gene regulatory genes (with consequent production of lower quantity of hemoglobin). One of the most frequent variants is a single nucleotide A-to-T mutation in the structural $\beta$-globin gene resulting in sickle cell hemoglobin, named hemoglobin $S$, which arises from the glutamic acid-tovaline substitution at position 6 in the $\beta$ subunit of hemoglobin. ${ }^{26}$ Generally, individuals with 1 hemoglobin S gene are phenotypically normal (sickle cell trait) and people who inherit 2 hemoglobin S genes have sickle cell (or Hb SS) disease. ${ }^{26}$ Sickle cell disease is associated with low hemoglobin values ( 7 or $8 \mathrm{~g} / \mathrm{dL}$ ), vaso-occlusive crises (which cause impaired blood flow and consequent local tissue hypoxia and even tissue/organ ischemia), long-term organ damage, and decreased survival. ${ }^{26}$
On the contrary, quantitative alterations in globin gene expression may result in thalassemia. Hereditary RBC-enzymopathies can also cause anemia. ${ }^{105-107}$ One of the more prevalent worldwide is glucose-6-phosphate dehydrogenase (G6PD) deficiency. ${ }^{108-110}$ More than 300 genetic variants of G6PD have been described. Most of the mutations are, however, rare. ${ }^{111}$ Hemolysis due to G6PD deficiency leads to decreased hemoglobin levels, and it is dependent on the class of the enzyme deficiency state and the magnitude of the oxidant impact. $^{26}$ The G6PD deficiency presents a geographic pattern, with the Class 3 variants (which are associated with mild to moderate enzyme deficit) being prevalent in populations of African ancestry. ${ }^{26}$

Physiologic and biologic aspects associated with anemia. The proportion of anemia attributable to the nutritional, infectious, and genetic causes discussed above may vary according to several physiologic and biologic aspects. In groups at high risk, multiple factors are frequently acting simultaneously to affect the risk of anemia. For instance, an imbalance between the nutrients needed for erythropoiesis and the higher nutrient demands for rapid growth, place children younger than 5 years at high risk for developing IDA. ${ }^{16,112,113}$ Healthy-term infants are reported to be generally born with adequate iron stores which can last approximately 6 months, depending on maternal iron status during pregnancy. ${ }^{8,26,114}$ It was reported that infants of anemic mothers were almost 6 times more likely to become anemic by the first year of life, even after adjusting for several confounding factors such as socioeconomic status, feeding practices, and morbidity. ${ }^{8}$ However, while generally considered adequate for the first 4 to 6 months of life, it should be considered that the amount of iron in breast milk may decrease through the course of breastfeeding period and may not be absorbed as efficiently as predicted..$^{8,115-117}$ Sequentially, the introduction of complementary foods should have appropriate quantity and bioavailability of iron and low levels of inhibitors of iron absorption, which could reduce the absorption. ${ }^{42,115,118,119}$ On the contrary, male infants may be at greater risk of lower hemoglobin concentrations and/or poor iron status as compared to female infants. ${ }^{16,120,121}$ An assessment of iron stores in infants during the first year of life found that male infants had consistently lower iron stores and estimated body iron, and higher rates of iron deficiency than female infants. ${ }^{120,122,123}$ It was suggested that in utero factors (potentially hormonal), could be influencing the status of iron at birth and also the erythropoietic activity. ${ }^{16}$ Furthermore, there are reports of high heterogeneity regarding the hemoglobin levels that should define anemia among different countries, particularly in tropical regions. ${ }^{124-126}$

Health determinants of anemia. The prevalence and distribution of anemia (particularly IDA) is considered to have (1) fundamental, (2) underlying, (3) intermediate, and (4) immediate determinants, involving a complex interplay of factors. (1) Fundamental determinants involve socioeconomic, political, climatic, and environmental conditions; (2) underlying determinants relate to agricultural factors (food/cash flow, crop yields, livestock), economic circumstances (regional/local wealth, equity/equality, literacy/education), and health policies (health coverage/insurance, control programs, fortification policies); (3) intermediate determinants relate to food availability (food security, household income/allocation/wealth, access to cereals/ vegetables/meat, food fortification, access to fortified complementary foods, meal/dietary patterns) and health care (access to health care, access to supplementations, health worker 
knowledge, sanitation and hygiene); (4) immediate determinants relates to nutritional micronutrient intake (iron content of food, iron availability, heme/nonheme content, consumption of inhibitors and enhancers), blood loss due to infections, and genetics. $^{27,52}$

From a general perspective, socioeconomic, behavioral, and environmental determinants can put some individuals and population groups at a higher risk of anemia. ${ }^{7,27,52}$ Socioeconomic status affects the prevalence of anemia through several pathways. For instance, poverty is associated with poor housing, water, sanitation and hygiene, and inadequate infrastructure that may lead to increased disease risk, adverse nutrition behaviors (such as poor dietary practices and poor dietary quality), and inadequate access to anemia prevention and treatment services (such as iron supplements, deworming, and insecticide treated bed nets). Women and children in the lowest wealth quintiles were found to have $25 \%$ and $21 \%$ higher risk of anemia, than those in the highest wealth quintiles. ${ }^{16}$ On the contrary, the low maternal education level may affect mother's ability to access and understand health and nutrition information, negatively affecting their children's quality of diet, or influence decision-making and compliance with recommended health and caretaking practices, being frequently associated with anemia. ${ }^{5,83,127}$ It has been also reported that some populations belonging to specific settings or ethnic, cultural, or religious groups may be at a greater risk of anemia due to having less opportunities for generating income, accessing education, health care, social services, water, sanitation, and hygiene, but also to being differentially exposed to infectious, having different dietary patterns, or a different genetic background. ${ }^{8,16}$ Gender inequality and cultural practices may also play a role in the development of anemia in children, occurring either when mothers face increased physiological risk (in turn associated with the factors mentioned above) or when the child feeding practices lead to differential risk of anemia between boys and girls. ${ }^{16}$

\section{Conclusion}

In Angola, the latest data on the prevalence of anemia in children younger than 5 years is worrisome. In addition, there is lack of reports regarding the main associated factors and there are no specifically designed interventions to address it. It should be considered that the internal results from government or other institution's studies may not be available and therefore are inaccessible. Nevertheless, the prevalence reported is indicative of a severe public health problem, but also have geographic heterogeneity and was frequently associated with infections. We did not found reports on the role of child feeding practices on the occurrence of anemia. To design an intervention in this misinformed scenario would result in unsustain spenditure of resources. Nevertheless, several interventions targeting nutritional anemias have already been tested in Africa and could be used as template. In this study, the rational and results of some important interventional strategies conducted in Africa have been resumed. We strongly recommend that educational plus therapeutic strategies, combining nutrition-specific and nutrition-sensitive approaches are considered.

\section{Acknowledgements}

The authors kindly acknowledge the support from the researchers José Pedro Gil, Diogo Costa, and José Figueiredo, who critically reviewed the manuscript and the financial support from Calouste Gulbenkian Foundation.

\section{Conflicts of interest}

The authors declare no competing interests.

\section{References}

[1] WHOThe Global Prevalence of Anaemia in 2011. Geneva, Switzerland: World Health Organization; 2015.

[2] Harika R, Faber M, Samuel F, Mulugeta A, Kimiywe J, Eilander A. Are low intakes and deficiencies in iron, vitamin A, zinc, and iodine of public health concern in Ethiopian, Kenyan, Nigerian, and South African children and adolescents? Food Nutr Bull. 2017;38:405-427.

[3] Saaka M, Galaa SZ. How is dietary diversity related to haematological status of preschool children in Ghana? Food Nutr Res. 2017;61: 1333389.

[4] Tiku YS, Mekonnen TC, Workie SB, Amare E. Does anaemia have major public health importance in children aged 6-59 months in the Duggina Fanigo district of Wolaita Zone, Southern Ethiopia? Ann Nutr Metab. 2018;72:3-11.

[5] Nambiema A, Robert A, Yaya I. Prevalence and risk factors of anemia in children aged from 6 to 59 months in Togo: analysis from Togo demographic and health survey data, 2013-2014. BMC Public Health. 2019;19:215.

[6] Kassebaum NJ. GBD 2013 Anemia CollaboratorsThe global burden of anemia. Hematol Oncol Clin North Am. 2016;30:247-308.

[7] Balarajan Y, Ramakrishnan U, Ozaltin E, Shankar AH, Subramanian SV. Anaemia in low-income and middle-income countries. Lancet. 2011;378:2123-2135.

[8] Ramakrishnan U. Nutritional Anemias-CRC Series in Modern Nutrition. Boca Raton, FL: CRC Press LLC; 2001.

[9] Kassebaum NJ, Jasrasaria R, Naghavi M, et al. A systematic analysis of global anemia burden from 1990 to 2010. Blood. 2014;123:615-624.

[10] DeMaeyer E, Adiels-Tegman M. The prevalence of anaemia in the world. World Health Stat Q. 1985;38:302-316.

[11] Brabin BJ, Premji Z, Verhoeff F. An analysis of anemia and child mortality. J Nutr. 2001;131:636S-645S. discussion 646S-648S.

[12] Zucker JR, Lackritz EM, Ruebush TK2nd, et al. Childhood mortality during and after hospitalization in western Kenya: effect of malaria treatment regimens. Am J Trop Med Hyg. 1996;55:655-660.

[13] Bwibo NO. Common causes of death in children at Mulago Hospital, Kampala, Uganda. Clin Pediatr (Phila). 1970;9:691-694.

[14] Commey JO, Dekyem P. Childhood deaths from anaemia in Accra, Ghana. West Afr J Med. 1995;14:101-104.

[15] McGregor IA, Williams K, Billewicz WZ, Thomson AM. Haemoglobin concentration and anaemia in young West African (Gambian) children. Trans R Soc Trop Med Hyg. 1966;60:650-667.

[16] WHONutritional anaemias: tools for effective prevention and control. Geneva, Switzerland: World Health Organization; 2017.

[17] Van Den Broeck J, Eeckels R, Vuylsteke J. Influence of nutritional status on child mortality in rural Zaire. Lancet. 1993;341:1491-1495.

[18] Eggert W1 ES, De Ceita F, Xavier J. The status of hemoglobin concentration and hematocrit in Angola children [in German]. Kinderarztl Prax. 1992;60:49-53.

[19] World Health OrganizationWorldwide Prevalence of Anaemia 19932005. Geneva, Switzerland: WHO; 2008.

[20] Cosep Consultoria Inquérito de Indicadores de Malária em Angola2011. Calverton, MD: Cosep Consultoria, Consa_ude e ICF Macro e ICF Macro; 2011.

[21] INE, MPDT. Inquérito de Indicadores M_ultiplos e de Sa_ude (IIMS) 2015-2016, Luanda-Angola. Principais Resultados. Maryland, EUA: Instituto Nacional de Estatística (INE), Ministério da Sa_ude (MINSA), Ministério do Planeamento e do Desenvolvimento Territorial (MPDT); 2017.

[22] Oliveira D, Ferreira FS, Atouguia J, Fortes F, Guerra A, Centeno-Lima $S$. Infection by intestinal parasites, stunting and anemia in school-aged children from Southern Angola. PLoS One. 2015;10:e0137327.

[23] Sousa-Figueiredo JC, Gamboa D, Pedro JM, et al. Epidemiology of malaria, schistosomiasis, geohelminths, anemia and malnutrition in the context of a demographic surveillance system in northern Angola. PLoS One. 2012;7:e33189.

[24] Lemos M, Fançony C, Moura S, et al. Integrated community-based intervention for urinary schistosomiasis and soil-transmitted helminthiasis in children from Caxito, Angola. Int Health. 2019.[Epub ahead of print].

[25] Guthmann JP, Cohuet S, Rigutto C, et al. High efficacy of two artemisinin-based combinations (artesunate + amodiaquine and 
artemether + lumefantrine) in Caala, Central Angola. Am J Trop Med Hyg. 2006;75:143-145.

[26] Bridges KR, Pearson HA. Anemias and Other Red Cell Disorders. McGraw-Hill Professional, 2007.

[27] Pasricha SR, Drakesmith H, Black J, Hipgrave D, Biggs BA. Control of iron deficiency anemia in low- and middle-income countries. Blood. 2013;121:2607-2617.

[28] Gibson RS, Donovan UM, Heath AL. Dietary strategies to improve the iron and zinc nutriture of young women following a vegetarian diet. Plant Foods Hum Nutr. 1997;51:1-16.

[29] Gibson RS, Hotz C. Dietary diversification/modification strategies to enhance micronutrient content and bioavailability of diets in developing countries. Br J Nutr. 2001;85 (suppl 2):S159-S166.

[30] Gibson RS, Anderson VP. A review of interventions based on dietary diversification or modification strategies with the potential to enhance intakes of total and absorbable zinc. Food Nutr Bull. 2009;30:S108S143.

[31] Allen LH. To what extent can food-based approaches improve micronutrient status? Asia Pac J Clin Nutr. 2008;17 (suppl 1):103105.

[32] WHO. Worldwide Prevalence of Anaemia 1993-2005: WHO Global Database on Anaemia. Geneva, Switzerland: WHO; 2008.

[33] Bhandari N, Bahl R, Mazumdar S, Martines J, Black RE, Bhan MK. Infant Feeding Study GroupEffect of community-based promotion of exclusive breastfeeding on diarrhoeal illness and growth: a cluster randomised controlled trial. Lancet. 2003;361:1418-1423.

[34] Aboud FE, Moore AC, Akhter S. Effectiveness of a community-based responsive feeding programme in rural Bangladesh: a cluster randomized field trial. Matern Child Nutr. 2008;4:275-286.

[35] Roy SK, Fuchs GJ, Mahmud Z, et al. Intensive nutrition education with or without supplementary feeding improves the nutritional status of moderately-malnourished children in Bangladesh. J Health Popul Nutr. 2005;23:320-330.

[36] Roy SK, Jolly SP, Shafique S, et al. Prevention of malnutrition among young children in rural Bangladesh by a food-health-care educational intervention: a randomized, controlled trial. Food Nutr Bull. 2007;28:375-383.

[37] Lassi ZS, Das JK, Zahid G, et al. Impact of education and provision of complementary feeding on growth and morbidity in children less than 2 years of age in developing countries: a systematic review. BMC Public Health. 2013;13 (suppl 3):S13.

[38] Imdad A, Yakoob MY, Bhutta ZA. Impact of maternal education about complementary feeding and provision of complementary foods on child growth in developing countries. BMC Public Health. 2011;11 (suppl 3):S25.

[39] Agbozo F, Colecraft E, Ellahi B. Impact of type of child growth intervention program on caregivers' child feeding knowledge and practices: a comparative study in Ga West Municipality, Ghana. Food Sci Nutr. 2016;4:562-572.

[40] Rao S, Joshi S, Bhide P, Puranik B, Asawari K. Dietary diversification for prevention of anaemia among women of childbearing age from rural India. Public Health Nutr. 2014;17:939-947.

[41] Penny ME, Creed-Kanashiro HM, Robert RC, Narro MR, Caulfield LE, Black RE. Effectiveness of an educational intervention delivered through the health services to improve nutrition in young children: a cluster-randomised controlled trial. Lancet. 2005;365: 1863-1872.

[42] Zijp IM, Korver O, Tijburg LB. Effect of tea and other dietary factors on iron absorption. Crit Rev Food Sci Nutr. 2000;40:371-398.

[43] WHOIndicators for Assessing Infant and Young Child Feeding Practices: Conclusions of a Consensus Meeting Held 6-8 November 2007 in Washington, DC, USA. Geneva, Switzerland: World Health Organization; 2007.

[44] Ferguson EL, Gibson RS, Thompson LU, Ounpuu S. Dietary calcium, phytate, and zinc intakes and the calcium, phytate, and zinc molar ratios of the diets of a selected group of East African children. Am J Clin Nutr. 1989;50:1450-1456.

[45] Bell JG, Keen CL, Lonnerdal B. Effect of infant cereals on zinc and copper absorption during weaning. Am J Dis Child. 1987;141:11281132.

[46] Gibson RS, Ferguson EL. Nutrition intervention strategies to combat zinc deficiency in developing countries. Nutr Res Rev. 1998;11: $115-131$.

[47] Gibson RS, Ferguson EL, Lehrfeld J. Complementary foods for infant feeding in developing countries: their nutrient adequacy and improvement. Eur J Clin Nutr. 1998;52:764-770.
[48] Gillooly M, Bothwell TH, Torrance JD, et al. The effects of organic acids, phytates and polyphenols on the absorption of iron from vegetables. Br J Nutr. 1983;49:331-342.

[49] Hallberg L, Brune M, Rossander L. Iron absorption in man: ascorbic acid and dose-dependent inhibition by phytate. Am J Clin Nutr. 1989;49:140-144.

[50] Brune M, Rossander-Hulten L, Hallberg L, Gleerup A, Sandberg AS. Iron absorption from bread in humans: inhibiting effects of cereal fiber, phytate and inositol phosphates with different numbers of phosphate groups. J Nutr. 1992;122:442-449.

[51] Pullan R, Brooker S. The health impact of polyparasitism in humans: are we under-estimating the burden of parasitic diseases? Parasitology. 2008;135:783-794.

[52] Pasricha SR, Vijaykumar V, Prashanth NS, et al. A community based field research project investigating anaemia amongst young children living in rural Karnataka, India: a cross sectional study. BMC Public Health. 2009;9:59.

[53] Bates I, McKew S, Sarkinfada F. Anaemia: a useful indicator of neglected disease burden and control. PLoS Med. 2007;4:e231.

[54] Stoltzfus RJ, Chwaya HM, Tielsch JM, Schulze KJ, Albonico M, Savioli L. Epidemiology of iron deficiency anemia in Zanzibari schoolchildren: the importance of hookworms. Am J Clin Nutr. 1997;65:153-159.

[55] Stoltzfus RJ, Albonico M, Chwaya HM, et al. Hemoquant determination of hookworm-related blood loss and its role in iron deficiency in African children. Am J Trop Med Hyg. 1996;55:399404.

[56] Friedman JF, Kanzaria HK, McGarvey ST. Human schistosomiasis and anemia: the relationship and potential mechanisms. Trends Parasitol. 2005;21:386-392.

[57] Magalhaes RJ, Clements AC. Mapping the risk of anaemia in preschool-age children: the contribution of malnutrition, malaria, and helminth infections in West Africa. PLoS Med. 2011;8:e1000438.

[58] Nussenblatt V, Semba RD. Micronutrient malnutrition and the pathogenesis of malarial anemia. Acta Trop. 2002;82:321-337.

[59] Ekvall H. Malaria and anemia. Curr Opin Hematol. 2003;10:108114.

[60] Dacal E, Saugar JM, De Lucio A, et al. Prevalence and molecular characterization of Strongyloides stercoralis, Giardia duodenalis, Cryptosporidium spp., and Blastocystis spp. isolates in school children in Cubal, Western Angola. Parasit Vectors. 2018;11:67.

[61] Doherty CP. Host-pathogen interactions: the role of iron. J Nutr. 2007;137:1341-1344.

[62] Hurlimann E, Houngbedji CA, Yapi RB, et al. Antagonistic effects of Plasmodium-helminth co-infections on malaria pathology in different population groups in Cote d'Ivoire. PLoS Negl Trop Dis. 2019;13: e0007086.

[63] Valice EM, Wiegand RE, Mwinzi PNM, et al. Relative contribution of schistosomiasis and malaria to anemia in Western Kenya. Am J Trop Med Hyg. 2018;99:713-715.

[64] Degarege A, Degarege D, Veledar E, et al. Plasmodium falciparum infection status among children with schistosoma in sub-Saharan Africa: a systematic review and meta-analysis. PLoS Negl Trop Dis. 2016;10:e0005193.

[65] Mooney JP, Galloway LJ, Riley EM. Malaria, anemia, and invasive bacterial disease: a neutrophil problem? J Leukoc Biol. 2019;105:645655.

[66] Jonker FAM, Te Poel E, Bates I, Boele van Hensbroek M. Anaemia, iron deficiency and susceptibility to infection in children in subSaharan Africa, guideline dilemmas. Br J Haematol. 2017;177:878883.

[67] Molyneux DH, Hotez PJ, Fenwick A. Rapid-impact interventions": how a policy of integrated control for Africa's neglected tropical diseases could benefit the poor. PLoS Med. 2005;2:e336.

[68] Dreyfuss ML, Stoltzfus RJ, Shrestha JB, et al. Hookworms, malaria and vitamin A deficiency contribute to anemia and iron deficiency among pregnant women in the plains of Nepal. J Nutr. 2000; 130:2527-2536.

[69] Al-Mekhlafi HM, Azlin M, Aini UN, et al. Protein-energy malnutrition and soil-transmitted helminthiases among Orang Asli children in Selangor, Malaysia. Asia Pac J Clin Nutr. 2005;14:188-194.

[70] Suzuki T. Iron deficiency anemia refractory to iron preparations. Rinsho Ketsueki. 2016;57:1881-1889.

[71] WHOWorldwide Prevalence of Anaemia 1993-2005. WHO Global Database on Anaemia. Geneva, Switzerland: World Health Organization; 2008. 
[72] Harding KB, Neufeld LM. Iron deficiency and anemia control for infants and young children in malaria-endemic areas: a call to action and consensus among the research community. Adv Nutr. 2012;3:551-554.

[73] Sazawal S, Black RE, Ramsan M, et al. Effects of routine prophylactic supplementation with iron and folic acid on admission to hospital and mortality in preschool children in a high malaria transmission setting: community-based, randomised, placebo-controlled trial. Lancet. 2006;367:133-143.

[74] Clark MA, Goheen MM, Cerami C. Influence of host iron status on Plasmodium falciparum infection. Front Pharmacol. 2014;5:84.

[75] Veenemans J, Milligan P, Prentice AM, et al. Effect of supplementation with zinc and other micronutrients on malaria in Tanzanian children: a randomised trial. PLoS Med. 2011;8:e1001125.

[76] Paganini D, Zimmermann MB. The effects of iron fortification and supplementation on the gut microbiome and diarrhea in infants and children: a review. Am J Clin Nutr. 2017;106:1688S-1693S.

[77] Florey L. Anemia as an Impact Measure of ITN Use among Young Children. DHS Analytical Studies No. 31. Calverton, MD: ICF International; 2012.

[78] Abhulimhen-Iyoha BI, Israel-Aina YT. Emergency blood transfusion in children in a tertiary hospital in Nigeria: indications, frequency and outcome. West Afr J Med. 2018;35:20-24.

[79] United Nations Development Programme, World Bank, World Health Organization. The prevention and management of severe anaemia in children in malaria-endemic regions of Africa: A review of research. Geneva, Switzerland: World Health Organization; 2001

[80] Guthmann JP, Ampuero J, Fortes F, et al. Antimalarial efficacy of chloroquine, amodiaquine, sulfadoxine-pyrimethamine, and the combinations of amodiaquine + artesunate and sulfadoxine-pyrimethamine + artesunate in Huambo and Bie provinces, central Angola. Trans R Soc Trop Med Hyg. 2005;99:485-492.

[81] Soares Magalhaes RJ, Langa A, Pedro JM, Sousa-Figueiredo JC, Clements AC, Vaz Nery S. Role of malnutrition and parasite infections in the spatial variation in children's anaemia risk in northern Angola. Geospat Health. 2013;7:341-354.

[82] Stoltzfus RJ, Albonico M, Chwaya HM, Tielsch JM, Schulze KJ, Savioli L. Effects of the Zanzibar school-based deworming program on iron status of children. Am J Clin Nutr. 1998;68:179-186.

[83] Bhargava A, Fox-Kean M. The effects of maternal education versus cognitive test scores on child nutrition in Kenya. Econ Hum Biol. 2003;1:309-319.

[84] Kabatereine NB, Brooker S, Koukounari A, et al. Impact of a national helminth control programme on infection and morbidity in Ugandan schoolchildren. Bull World Health Organ. 2007;85:91-99.

[85] Stoltzfus RJ, Chway HM, Montresor A, et al. Low dose daily iron supplementation improves iron status and appetite but not anemia, whereas quarterly anthelminthic treatment improves growth, appetite and anemia in Zanzibari preschool children. J Nutr. 2004;134:348356.

[86] Gyorkos TW, Maheu-Giroux M, Blouin B, Casapia M. Impact of health education on soil-transmitted helminth infections in schoolchildren of the Peruvian Amazon: a cluster-randomized controlled trial. PLoS Negl Trop Dis. 2013;7:e2397.

[87] Al-Delaimy AK, Al-Mekhlafi HM, Lim YA, et al. Developing and evaluating health education learning package (HELP) to control soiltransmitted helminth infections among Orang Asli children in Malaysia. Parasit Vectors. 2014;7:416

[88] Dawson EM, Sousa-Figueiredo JC, Kabatereine NB, Doenhoff MJ, Stothard JR. Intestinal schistosomiasis in pre school-aged children of Lake Albert, Uganda: diagnostic accuracy of a rapid test for detection of anti-schistosome antibodies. Trans $\mathrm{R}$ Soc Trop Med Hyg. 2013;107:639-647.

[89] Stothard JR, Sousa-Figueiredo JC, Navaratnam AM. Advocacy, policies and practicalities of preventive chemotherapy campaigns for African children with schistosomiasis. Expert Rev Anti Infect Ther. 2013;11:733-752.

[90] Stothard JR, Gabrielli AF. Schistosomiasis in African infants and preschool children: to treat or not to treat? Trends Parasitol. 2007;23:83-86.

[91] Stothard JR, Sousa-Figueiredo JC, Betson M, Bustinduy A, ReinhardRupp J. Schistosomiasis in African infants and preschool children: let them now be treated!. Trends Parasitol. 2013;29:197-205.

[92] Stothard JR, Sousa-Figueiredo JC, Betson M, et al. Closing the praziquantel treatment gap: new steps in epidemiological monitoring and control of schistosomiasis in African infants and preschool-aged children. Parasitology. 2011;138:1593-1606.
[93] Asaolu SO, Ofoezie IE. The role of health education and sanitation in the control of helminth infections. Acta Trop. 2003;86:283-294.

[94] Alvarado BE, Gomez E, Serra M, et al. Evaluation of an educational strategy on malaria in rural areas of the Colombian Pacific Coast [in Spanish]. Biomedica. 2006;26:342-352.

[95] Amoran OE. Impact of health education intervention on malaria prevention practices among nursing mothers in rural communities in Nigeria. Niger Med J. 2013;54:115-122.

[96] Lee YH, Jeong HG, Kong WH, et al. Reduction of urogenital schistosomiasis with an integrated control project in Sudan. PLoS Negl Trop Dis. 2015;9:e3423.

[97] Foote EM, Sullivan KM, Ruth LJ, et al. Determinants of anemia among preschool children in rural, western Kenya. Am J Trop Med Hyg. 2013;88:757-764.

[98] Coutinho SB, De Lira PI, D Carvalho Lima M, Ashworth A. Comparison of the effect of two systems for the promotion of exclusive breastfeeding. Lancet. 2005;366:1094-1100.

[99] Tobgay T, Pem D, Dophu U, et al. Community-directed educational intervention for malaria elimination in Bhutan: quasi-experimental study in malaria endemic areas of Sarpang district. Malar J. 2013;12:132.

[100] Abegunde D, Orobaton N, Bassi A, et al. The impact of integrated community case management of childhood diseases interventions to prevent malaria fever in children less than five years old in Bauchi State of Nigeria. PLoS One. 2016;11:e0148586.

[101] Humphrey JH, Mbuya MNN, Ntozini R, et al. Independent and combined effects of improved water, sanitation, and hygiene, and improved complementary feeding, on child stunting and anaemia in rural Zimbabwe: a cluster-randomised trial. Lancet Glob Health. 2019;7:e132-e147.

[102] Null C, Stewart CP, Pickering AJ, et al. Effects of water quality, sanitation, handwashing, and nutritional interventions on diarrhoea and child growth in rural Kenya: a cluster-randomised controlled trial. Lancet Glob Health. 2018;6:e316-e329.

[103] Rees DC, Williams TN, Gladwin MT. Sickle-cell disease. Lancet. 2010;376:2018-2031.

[104] Thom CS, Dickson CF, Gell DA, et al. Hemoglobin variants: biochemical properties and clinical correlates. Cold Spring Harb Perspect Med. 2013;3:a011858.

[105] Brito MTC, Santos B, Veiga L. Glucose-6-phosphate dehydrogenase deficiency in children from 0 to 14 years hospitalized at the Pediatric Hospital David Bernardino, Luanda, Angola. Pharmacogenom Pharmacoproteom. 2014;5:2.

[106] Eziefula AC, Pett H, Grignard L, et al. Glucose-6-phosphate dehydrogenase status and risk of hemolysis in Plasmodium falciparum-infected African children receiving single-dose primaquine. Antimicrob Agents Chemother. 2014;58:4971-4973.

[107] Phillips J, Henderson AC. Hemolytic anemia: evaluation and differential diagnosis. Am Fam Physician. 2018;98:354-361.

[108] Howes RE, Piel FB, Patil AP, et al. G6PD deficiency prevalence and estimates of affected populations in malaria endemic countries: a geostatistical model-based map. PLoS Med. 2012;9: e1001339.

[109] Nkhoma ET, Poole C, Vannappagari V, Hall SA, Beutler E. The global prevalence of glucose-6-phosphate dehydrogenase deficiency: a systematic review and meta-analysis. Blood Cells Mol Dis. 2009;42:267-278.

[110] Briolant S, Pradines B, Basco LK. Role of primaquine in malaria control and elimination in French-speaking Africa [in French]. Bull Soc Pathol Exot. 2017;110:198-206.

[111] Beutler E. G6PD deficiency. Blood. 1994;84:3613-3636.

[112] Camaschella C. Iron deficiency. Blood. 2019;133:30-39.

[113] Lopez A, Cacoub P, Macdougall IC, et al. Iron deficiency anaemia. Lancet. 2016;387:907-916.

[114] McCarthy EK, Kenny LC, Hourihane JOB, Irvine AD, Murray DM, Kiely ME. Impact of maternal, antenatal and birth-associated factors on iron stores at birth: data from a prospective maternal-infant birth cohort. Eur J Clin Nutr. 2017;71:782-787.

[115] Griffin IJ, Abrams SA. Iron and breastfeeding. Pediatr Clin North Am. 2001;48:401-413.

[116] Meinzen-Derr JK, Guerrero ML, Altaye M, Ortega-Gallegos H, RuizPalacios GM, Morrow AL. Risk of infant anemia is associated with exclusive breast-feeding and maternal anemia in a Mexican cohort. J Nutr. 2006;136:452-458.

[117] Pizarro F, Yip R, Dallman PR, Olivares M, Hertrampf E, Walter T. Iron status with different infant feeding regimens: relevance to screening and prevention of iron deficiency. J Pediatr. 1991;118:687-692. 
[118] Pizarro F, Olivares M, Hertrampf E, et al. Factors which modify the nutritional state of iron: tannin content of herbal teas [in Spanish]. Arch Latinoam Nutr. 1994;44:277-280.

[119] Gibson RS, Bailey KB, Gibbs M, Ferguson EL. A review of phytate, iron, zinc, and calcium concentrations in plant-based complementary foods used in low-income countries and implications for bioavailability. Food Nutr Bull. 2010;31:S134-S146.

[120] Wieringa FT, Berger J, Dijkhuizen MA, et al. Sex differences in prevalence of anaemia and iron deficiency in infancy in a large multicountry trial in South-East Asia. Br J Nutr. 2007;98:1070-1076.

[121] Yalcin SS, Dut R, Yurdakok K, Ozmert E. Seasonal and gender differences in hemoglobin value in infants at 5-7 months of age. Turk J Pediatr. 2009;51:572-577.

[122] Ziegler EE, Nelson SE, Jeter JM. Iron stores of breastfed infants during the first year of life. Nutrients. 2014;6:2023-2034.
[123] Domellof M, Lonnerdal B, Dewey KG, Cohen RJ, Rivera LL, Hernell O. Sex differences in iron status during infancy. Pediatrics. 2002;110: 545-552.

[124] Addo Y, Yu EX, Williams A, et al. Evaluation of hemoglobin cutoffs for defining anemia in a multinational sample of healthy individuals: the BRINDA Project (OR07-07-19). Curr Dev Nutr. 2019;3:3.

[125] Jorgensen JM, Crespo-Bellido M, Dewey KG. Variation in hemoglobin across the life cycle and between males and females. Ann N Y Acad Sci. 2019;1450:105-125.

[126] Humberg A, Kammer J, Mordmuller B, Kremsner PG, Lell B. Haematological and biochemical reference intervals for infants and children in Gabon. Trop Med Int Health. 2011;16:343-348.

[127] Melku M, Alene KA, Terefe B, et al. Anemia severity among children aged 6-59 months in Gondar town, Ethiopia: a community-based cross-sectional study. Ital J Pediatr. 2018;44:107. 